\title{
JUVENILE PRISON IN PARALLEL LEGISLATION
}

\section{Mitar Lutovac ${ }^{41}$, Ivan Joksic ${ }^{42}$, Borislav Bojic ${ }^{43}$}

\begin{abstract}
The need for punishment of juveniles occurred from the time when there was no clear line separating them from the adult criminal population. At the same time, the evolution of the juvenile punishment is not in itself involve substantial changes to their criminal status. On the contrary, the status of minors in society did not show serious differences regarding the status of young adults, as well as the adult elderly. On the other hand, on the ground of their punishment is recorded deviations that go in the direction of application of mild corporal punishment. Closing the minor was performed in a physically separate parts of the general penal institutions with the use of a lower degree of restrictions while serving juvenile prison.

Due to the different treatment of minors during the evolution of their criminal status leads to their different treatment in comparative law. That is why we are witnessing the existence of numerous differences in the juvenile punishment in some countries in the world. On the European continent there is a wide range of different legal solutions when it comes to punishing juveniles. There are considerable differences in the procedure pronouncing juvenile prison and in particular penal treatment of juveniles in penitentiary institutions. For these reasons, the author has decided to show the basic statutory provisions in the part that relates to the issue of punishment of minors in the legislation of individual countries.
\end{abstract}

KEYWORDS: punishment of juveniles, juvenile prison, penal treatment, retention of juvenile imprisonment, the court.

JEL: K42, K14

UDC: 343.26-053.6

\footnotetext{
${ }^{41}$ University Union Nikola Tesla, Faculty of Business and Industrial Management Belgrade Serbia, e-mail: gsmmitar@gmail.com

${ }^{42}$ Law Faculty of Economics and Justice University Business Academy,Novi Sad Serbia,e-mail: ijoksic@hotmail.rs

${ }^{43}$ Law Faculty of Economics and Justice University Business Academy,Novi Sad Serbia,e-mail: kruzerns@hotmail.com
} 


\section{Introduction}

\section{Canada}

Canada is a country where the legal scene is a specific combination of two legal systems: the Anglo-Saxon and European-continental. In this duality are located institutes, both general and juvenile criminal law. The last decade was marked by the implementation of the new Law on the prosecution of minors in 2002. According to the provisions of this Act, the punishment of juvenile imprisonment may be imposed under violent criminal offenders, perpetrators of serious crimes, as well as juvenile recidivists. The minor can be punished with a prison sentence, except in the following cases:

- When he committed a criminal offense involving violence,

- When the conditions have been met for imposing a non-prison sentence,

- When he committed a serious criminal offense prosecuted under indictment and when history of offenses indicates a pattern of repetition of offenses, or

- In exceptional cases, when a juvenile has committed a criminal offense prosecuted under indictment and aggravated offenses are such that you can not impose any other sentence to prison, which would be in accordance with the prescribed purpose and principles of punishment. In addition, the law requires that a judge must explain the decisive reasons due to which it is considered that in this case, that particular juveniles should be punished by deprivation of liberty.

The law on the prosecution of minors expands range of penalties that may be imposed on minors. Introduced two new types of penalties: deferred prison sentence and imprisonment, and deprivation of liberty under intensified rehabilitation and supervision.

Deferred prison sentence and a prison to a juvenile serving a sentence in the community with their obligation to carry out orders and commitments that are defined. If the conditions imposed are not executed a juvenile can be sent to prison to serve his sentence.

Deprivation of liberty under intensified rehabilitation and monitoring represents the maximum sentence under the new law on the criminal prosecution of juveniles. This penalty is imposed only juvenile perpetrators of more serious and violent crimes. In addition, it may be imposed in the following cases:

- Minor is found guilty of murder, attempted murder, manslaughter, serious sexual offense, or repeated serious crimes,

- Minor suffering from mental or psychological disorder or emotional disturbance,

- Made an individual treatment plan for the minor, and

- There is an appropriate program and a minor is eligible to take part in it.

Certain new are being introduced in terms of sentencing juveniles. The juvenile court previously determined guilt minors and then the same person may impose a penalty prescribed for adults. Age-age suffered some changes in terms of lowering the age limit to 14 years, provided that the province can raise the specified age limit to 15 or 16 years. In addition, the Prosecutor may notify juvenile court not to seek a sentence intended for adults, with regard to a criminal offense committed by a person older than 14 years, in which case the court may waive the imposition of penalties provided for adults.

Stipulate the obligation of the court to first review whether the punishment for juveniles may be sufficient for its complete rehabilitation. If the court a positive assessment, it must 
impose a sanction envisaged for minors. An integral part of the juvenile prison sentence consists of two phases: the period of serving the sentence in an appropriate penal institution and the period of supervision in the community. The juvenile judge shall at the sentencing explicitly specify and explain in a public trial, that part of the sentence the juvenile is serving within correctional institutions, a part of the community under supervision. If a minor violates the conditions within the part of the sentence serving under the supervision of the community, provided several possible situations: changes the conditions under which the juvenile is serving this part of the sentence, his return to the correctional facility, as well as setting new conditions under which a minor is the time supervision in the community.

There is a possibility that the minor is not supporting part of the sentence under supervision in the community. In this case, prior to the commencement of serving the second part of the sentence, the court may ask the minor to remain in the correctional institution. This legal option is applicable to a minor in a situation where there is a reasonable fear that the minor before the expiry of the sentence to commit a criminal act that resulted in death or serious bodily injury.

The convicted juvenile can get parole for rehabilitation and preparation for future reintegration into society. The law restricted the duration of the discharge in 30 days, with which the provincial director, after reviewing the entire case file, could again renew.

In accordance with the tendency of individualization in sentencing recent Canadian juvenile law has prescribed specific rules for the execution of institutional penalties against minors. Accordingly, the court in sentencing specifically decides whether to send juveniles in correctional facility, open or closed. Criminal prosecution of juveniles offers new solutions and possibilities in respect of the execution of punishment of minors who during her lifetime to become an adult. That is a possibility to a minor, he or she attains 20 years, be moved to a facility for adults to proceed with the enforcement of the sentence. In a word, the new juvenile legislation in Canada provides a wide range of possibilities for the application of new or revised and existing solutions in the field of juvenile punishment which is specifically discussed in public.

\section{Germany}

The criminal justice status of juveniles in Germany is regulated by several pieces of legislation: The Law on court proceedings against minors, the Criminal Procedure Code Federal Republic of Germany to the Law on Courts. Punishing minors envisaged under the fourth chapter, entitled - Penalties for minors. In addition, the juvenile imprisonment is a last resort (ultima ratio), when used all other legal options in terms of sanctioning minors. This penalty can be imposed on minors aged 14 to 21 years. The legislator, in this case, predicted two possibilities:

Minors aged 14 to 17 years it is possible to avoid a prison sentence of 6 months to 5 years, or 10 years ago when a minor does a serious crime punishable by imprisonment not exceeding 10 years,

Minors aged 18 to 21 years shall be imposed a maximum period of imprisonment to 10 years.

It is necessary to fulfill two conditions for the imposition of sentences of juvenile prison (paragraph $17 \S 2 \mathrm{JGG)}$ : 
The presence of harmful circumstances that the juvenile is expressed in the exercise of the crime, so it is not "enough" imposed on some of the corrective measures or means,

The existence of a high degree of guilt in the minor offender, so it is necessary to impose a penalty.

When pronouncing juvenile prison court are available all the possibilities. The first option refers to the imposition of unsuspended sentences of juvenile prison. Another option includes a conditional suspended sentence for juveniles in a sentence of up to one year (paragraph $21 \mathrm{JGG}$ ). The judge will postpone the enforcement of the sentence on probation period if it can be expected that the conviction itself and without the enforcement of the educational act as a warning to the minors to probation period (trials) as well as future repair their behavior. In addition, the court should take into account the personality of the minor, his earlier life, her behavior after the offense, the conditions in which he lived and the expected impact achieved by applying delay execution of the sentence on juveniles. The conditional postponement of sentence, which has elements of a suspended sentence in our criminal legislation, can last up to two years.

In the end, the purpose of juvenile imprisonment is defined as the education of minors to continue to lead an honorable and responsible life, and at the same time the basis of such education should be the order, work, teaching, physical exercise and appropriate use of leisure time. The stated purpose is entirely in the spirit of German legislation which juveniles treated as a personality that should be administered treatment that includes educational and pedagogical work with juvenile convicts. In this sense, we can safely conclude direct liaison with the solutions present in our juvenile criminal law. "With regard to the social reintegration of juvenile convict's primary objective execution of juvenile prison, it is necessary to fully realize the educational function of punishment."

\section{France}

In France the criminal law status of juveniles is regulated by the Regulation on delinquent children since 1945, which was amended several times. In doing so, the punishment of minors is foreseen in Articles 2 and 20 of the Regulation, which states that may be punished criminally responsible from the age of a minor 13 years of life. The punishment of juveniles also includes the possibility of imposing fines, pursuant to Article 20-3 of the Regulation. A minor older than 16 years who is charged with crimes trial Assizes Court for minors. However, the sentence imposed by the juvenile court the penalty prescribed in the general criminal law. In terms of duration, provided that the penalty may not be the same length as for adult offenders. It is interesting to point out the specific limitations clearly age of minors. Thus, a minor older than 13 years can be imposed is higher than half of retribution. In the case of the life in prison sentence, juvenile courts can not impose a sentence greater than 20 years in prison.

Summarizing the above, we see that in France the power of the general regime of punishment of juvenile offenders. Certain discrepancies with regard to punishment of minors in relation to adults, are related to the treatment of the minority of such mitigating circumstances during sentencing. In addition, the juvenile offender is older than 16 years is subject to the general regime of punishment and execution of the sentence that applies to adults so that, in the above case, the victim is a minor ceases to be a mitigating circumstance. 


\section{Croatia}

In Croatia, the criminal and legal status of minors is regulated by the new Law on Juvenile Courts since 2011. According to the provisions of Article 6, paragraph 2 of the Law on Juvenile Courts, the purpose of juvenile imprisonment is to take measures of education and vocational training of the minor offender affect the further development of his personality and strengthen his personal responsibilities for the maintenance of the repeated commission of crimes as well as to deter others from committing crimes.

Imposition of juvenile detention requires the fulfillment of planned objective and subjective conditions. Objective condition refers to the potential penalty for committing a criminal offense (three years or more). The subjective requirement includes the obligation to meet more preconditions: it was a senior juvenile, and given the nature and gravity of the offense and a high degree of culpability of the offender would not be justifiable to apply an educational measure, it is necessary to apply the punishment.

Sentencing of juvenile imprisonment can be done in the time span of less than six months nor more than five years. However, the Law on Juvenile Courts (Article 25) provides for certain exceptions:

If it is a criminal offense punishable by imprisonment, or a concurrence of at least two offenses for which a sentence of imprisonment of ten years, juvenile detention can last up to ten years (paragraph 1);

The court can not be measured in juvenile detention longer than as prescribed punishment for the offense, but is not required to measure the minimum prescribed and penalties (paragraph 2).

Special rules are provided for the imposition of the juvenile prison in concurrence of offenses in three cases:

A single sentence of juvenile prison without first establishing penalties for each individual criminal offense,

When for a criminal offense should be sentenced to a juvenile prison for another educational measure, the court shall impose only a sentence of juvenile imprisonment,

If after pronouncing juvenile prison finds that the juvenile before or after sentencing did a crime, the court refers to the rules laid down in the first case.

Conditional release can be imposed upon thirds of the sentence of juvenile prison sentence. Duration of conditional release is limited to the expiration of the juvenile prison sentence imposed. County court which pronounced the juvenile prison or whose seat of municipal court that imposed the punishment shall decide on the conditional release of the minor convicts. Revocation of parole is possible if the convicted person commits one or more criminal offenses for which a prison sentence of six months or juvenile imprisonment of six months.

It is interesting to point out the presence of a specific legal institute called "holdup pronouncing juvenile prison." The institute consists in the power of the court to be imposed or to determine that the juvenile guilty of committing a criminal offense and simultaneously postponed sentencing to juvenile prison, if it is considered that the imposition of guilt accompanied by the threat of subsequent sentencing juvenile offender can be deterred from re-committing criminal acts. The juvenile court may, in the framework of retention, pronounced educational measure of intensive supervision, referral to a disciplinary center 
and one or more special obligations can not last longer than the probation period (Article 28, Paragraph 1 of the Law on Juvenile Courts). Juvenile imprisonment may be imposed later if the time fixed by the court, which may not be less than one year nor more than three years (probation period), commit another criminal offense or opposes the application of the imposed corrective measures. In addition to regular, juvenile imprisonment is possible and subsequently imposed in two cases:

- If in the time specified by the court (probation period) a minor which is reserved to the imposition of the punishment of juvenile custody commits a new criminal offense,

- If you oppose the execution of the pronounced measure or without justifiable reasons will not serve the protective measure imposed it by the subject to the imposition of juvenile detention.

The law on juvenile courts has predicted the possibility of imposing security measures against a juvenile who was sentenced to juvenile prison. However, prescribes two constraints: security measure ban on performing profession, activity or duty can not be imposed at all, and prohibited from driving a motor vehicle may only be applied to an older juvenile. Medical security measure of compulsory psychiatric treatment and mandatory treatment of addiction lasts until the cessation of reasons were applied. In any case, the duration of these security measures stop with the execution of juvenile detention or expiration of the probation period of retention in juvenile prison, with what can not last longer than three years. The execution of juvenile prison is fully in line with European and international regulations. Croatia has built a special system of correctional institutions for juveniles, as follows:

- Požega Penitentiary Department for execution of juvenile prison sentence (prison unit)

- A prison in Pozega (semi-open section)

- Penitentiary in Valtura (open division).

At each facility, there are special programs of individual treatment of juvenile convicts. In doing so, the program for each prisoner must contain the following particulars:

The risk assessment during the execution of the prison sentence of which depends on referral to the prison according to the degree of security (closed, semi-open)

- Work ability, work habits, type of job and working conditions in which the inmate may be transferred,

- Level of education and the need for education or vocational training,

- Health, the need for treatment,

- Participation in specific programs (drug addiction, alcohol, suffering from PTSD), by court decision or assessment of an expert team,

- The need for specific psychological, psychiatric, social or legal assistance,

- A proposal for special forms of individual and group work,

- Contents and forms of leisure (cultural and sports activities)

- Contact with the outside world (correspondence, phone calls, visits to family and other persons)

- A program of preparation for release to liberty and assistance after release.

Depending on the success achieved correctional institution may introduce changes in the existing programs of action. At the same time, followed the progress of the convicts and the possibilities of its possible release on parole. 


\section{Republic Serbia}

In the Republic of the Serbian criminal and legal status of minors and the problems of their punishment is regulated by the newly adopted Law on Protection and Treatment of Children and Juveniles in criminal proceedings. The new juvenile criminal legislation maintained the principle of exceptional punishment (older) minor. According to Article 31 of the Law, the general purpose of criminal sanctions against minors is to ensure the protection, care, assistance and supervision, as well as providing general and vocational training to foster the development and empowerment of personal responsibility of juveniles, provide education and proper development of his personality, ensure the reintegration of minors in the community. In paragraph 2 of the same article, the general purpose of criminal sanctions against minors is complemented by a special that only applies to juvenile prison, and that is to exercise increased influence on juvenile offender offender not to commit criminal acts, as well as to deter other juveniles committing criminal offenses. "By complementing the general purpose of criminal sanctions for specific ends in juvenile prison, the legislator has specifically accented the importance, but also the uniqueness of this sentence in the system of criminal sanctions against minors."

The new Law on Juvenile Justice (Article 50) requires the fulfillment of four conditions for the application of punishment against minors, namely:

- That the offender is an older juvenile, ie. that is a minor at the time of the offense attained 16 years but had not reached 18 years of age,

- It is an older juvenile has committed a criminal offense which carries a sentence of imprisonment of five years,

- That there is a high degree of criminal responsibility of minors,

- Extract from the court that because of the serious consequences of work and the high degree of criminal responsibility would not be justified to pronounce a correctional measure on a minor.

Juvenile imprisonment can be imposed for a period ranging up to five years. However, it is possible to impose such a sentence longer than the prescribed time. For a criminal offense which carries a penalty of imprisonment or for concurrence of at least two criminal acts, for which a sentence of imprisonment of 10 years, juvenile detention can last up to 10 years. In determining the punishment for a senior juvenile for a criminal offense, the court may not impose juvenile imprisonment for a term exceeding that of imprisonment prescribed for the crime, but it is not bound by the minimal measure of that punishment. In sentencing juvenile imprisonment, the court shall consider all the circumstances affecting the sentence being longer or shorter in accordance with Article 37 paragraph 1 and 2 of the Criminal Code.

"A significant step towards the actualization of modern legal possibilities juvenile prison sentence in the Republic of Serbian, represents a premiere introduction of a new institute deferred sentencing the juvenile prison". The court may impose a sentence of juvenile prison and at the same time determined that he would not execute when we can reasonably expect that the threat of subsequent sentencing may affect the juvenile offender not to commit criminal acts. With a full sentence, the court may impose any of the educational measures of intensified supervision and to determine to that extent one or more special obligations. However, the court may subsequently order the execution of juvenile imprisonment if a juvenile during which the court orders, which may not be less than one nor more than three years (probation period), commits another offense or if he refuses to comply with the imposed educational measure increased supervision or execution of specific obligations. After the 
expiry of at least one year of probation period, the court may, after obtaining the opinion of the guardianship authority, finally withdraw from the sentencing to juvenile prison.

The subsequent sentencing to juvenile prison is planned in two situations:

- The minor which is delayed sentencing to juvenile prison is convicted or he is pronounced an educational measure because of the new criminal offense committed before the expiry of the probation period, the court shall impose a sentence for the previously committed act, if, due to the newly imposed sentence or correctional measure, it necessary to deter minors from the commission of offenses,

- The minor despite the warning Court refuses to comply with the imposed educational measure or execution of specific obligations.

On the other hand, when the court does not impose subsequent juvenile prison, then decide they remain in force already imposed measures or impose other measures. Furthermore, juvenile imprisonment may be imposed no later than six months after the expiry of the probationary period, or after completion of the procedure due to a new criminal offense.

Mode of execution of juvenile detention is conducted in special correctional facilities for juveniles. According to Article 176 of the Act provides for the possibility of subsequent stay in a correctional institution for juveniles, to education and vocational training, convicts whose performances majority in two cases:

- Sentenced to juvenile imprisonment in a correctional institution for juvenile can remain up to the age of 23 , and then if the sentence is served, it shall proceed in accordance with Article 175 of this law (paragraph 1);

- Exceptionally, in a correctional institution for juveniles convicted person may remain even after reaching the age of 23 years, if it is necessary for the completion of schooling or vocational training, or if the remainder of their sentence not exceeding six months but not longer than the age of 25 years $(\S 2)$.

In a word, the execution of juvenile imprisonment shall be subject to the general regime provided for in the new Law on Juvenile Justice with the additional application of the relevant provisions of the applicable Law on Execution of Criminal Sanctions (Chapter XII).

\section{Montenegro}

Montenegro is not a matter of minors allocated in a separate law, but their criminal and legal status is regulated by the general criminal law. In this respect, the Criminal Code of Montenegro, in Chapter VI, contains provisions to regulate the status of juveniles, the manner and modalities of their sanctions. The common denominator of criminal policy towards juveniles is reflected in the application of the principles of excellence in their punishment. Accordingly, it can only punish a senior juvenile who has committed a criminal offense for which the law prescribes a prison sentence of over five years, if, due to the high degree of guilt of the offender and the gravity of the offense would not be justifiable to apply an educational measure (Article $100 \mathrm{CC}$ ).

Duration of juvenile imprisonment is limited to the time range of six months to eight years. However, the court may not impose juvenile imprisonment for a longer period of imprisonment prescribed for a criminal offense, but is not bound by the minimal measure of that punishment (Article 103, paragraph 2 of the Criminal Code of Montenegro). In relation 
to offenses carrying a statutory penalty of imprisonment of ten years, may be sentenced to juvenile imprisonment of up to ten years.

Provides for three modes of sentencing juvenile imprisonment for concurrent criminal offenses and that (Article 104 of the Criminal Code):

- If you are an older juvenile to do more criminal offenses in concurrence, the court finds that for some of them to be sentenced to a juvenile prison, weigh for all crimes a single sentence,

- If for some of the committed criminal offenses must be sentenced to a juvenile prison, and for other educational measures, the court shall, for all offenses in concurrence imposed a sentence of juvenile imprisonment,

- If, after the sentence of juvenile prison finds that the convicted person before or after its imposition has committed another criminal offense, apply the rules as set forth above.

The issue of enforcement of juvenile detention in Montenegro is resolved through the application of general rules for the execution of imprisonment. Consequently, the Law on Execution of Criminal Sanctions regulates the question of the execution of juvenile prison sentence in the fifth chapter. General rules for execution of imprisonment related to adult convicts: committal to prison, reception of prisoners, their location and operation, contact with the outside world, disciplinary and material responsibility, and are applied in the execution of juvenile detention. However, exceptions to the application of the general rules for the execution of imprisonment exist in two cases, the execution of juvenile detention:

- Minor convict who behaves appropriately and demonstrates a commitment to learning and work, organization officer may grant leave to visit their parents and other close relatives. Absence can be given a maximum of two times in one year, provided that its duration is limited in time until 14 days after each absence.

- Disciplinary punishment of juvenile convicts coming to the fore in terms of disciplinary punishment of solitary confinement. Pursuant to Article 71 of the Law on Execution of Criminal Sanctions "convicted juvenile may exceptionally be imposed a disciplinary punishment of solitary confinement to 10 days, and if during the term of juvenile imprisonment minor has come of age this punishment may last up to 30 days."

\section{Conclusion}

The punishment of minors is the last step on the long road struggle of society with youth crime. Excellence in punishing juveniles are reflected in the application of diversion and educational measures aimed at minimal restrictions to achieve the best results. In this regard, the punishment of juvenile represents the ultimate means of applying re-social active treatment affects their re-education and training for life in freedom. Criminal status observed through the prism of the right of the state to punish them is one of the important issues in comparative legislations. Regardless of the legal system to which they belong, state in their juvenile and general national criminal legislation foresee the possibility of applying juvenile prison. In doing so, there are almost no countries that are in the same manner regulated material, procedural and enforcement aspects of the juvenile prison. As a reminder, in Canada and Germany, the special laws cover the entire matter on the criminal responsibility of minors. On the other hand, in France several decades old regulation on child delinquents regulates criminal law status, and the system of criminal sanctions 
against minors. Countries of the former Yugoslavia are modeled after European incorporate into their legislation specific legislation on the criminal liability of minors. The register of criminal sanctions retained an exceptional possibility of punishment of minors over juvenile prison. Depending on the approach to the issue of punishment of juveniles in each of the countries of the former Yugoslavia we find modifications in terms of material, process and particularly the executive aspects of juvenile detention. However, the common denominator of various legal provisions also evident in the provision of broad opportunities for the application of high-quality treatment in correctional institutions leading in this account of the needs of juvenile convicts and possibilities of the community.

\section{References}

[1] Joksić, I., "Juvenile prison as" ultima ratio "in sanctioning juvenile delinquency," Bulletin of the Bar Association of Vojvodina 9/2010.

[2] Joksić, I., "The punishment of juveniles in the criminal legislation of the Republic of Serbian" Security 2/2011.

[3] Kos, J., "The execution of juvenile sanctions," Croatian Annual of Criminal Law and Practice 2/2006.

[4] Law on Execution of Criminal Sanctions R. Serbian Official Gazette of RS, no. 12/10.

[5] Law on Execution of Criminal Sanctions Republic of Montenegro, Official Gazette of the Republic. 25/94, 29/94, 69/03, 65/04. Official Gazette of Montenegro. 32/11.

[6] Law on Juvenile Courts of the Republic of Croatian, Official Gazette of the Republic of Croatia no. 84/11.

[7] Law on Protection and Treatment of Children and Juveniles in criminal proceedings R. Serbian Official Gazette of RS, no. 13/10.

[8] Ordonnance no. 45-174 du mar. 1945 relative à l'enfance Delinquante. Version consolidée in'll octobre, 2007.

[9] Pavlovic, D., Law on court proceedings against juveniles, the Law on Criminal Procedure of the Federal Republic of Germany to the Law on Courts, Marketing Center, Belgrade, in 1997.

[10] Pru, Ž., Canadian law on the prosecution of juveniles, International scientific conference "Criminal legal issues of juvenile delinquency" organized by the Serbian Association for Criminal Law theory and practice, Belgrade, 2008.

[11] Radulovic, Lj., Juvenile Criminal Law, Faculty of Law, Belgrade, 2010.

[12] The Criminal Code of the Republic of Montenegro, Official Gazette of the Republic. 70/03, 13/04, 47/06. Official Gazette of Montenegro. 40/08 and 25/10.

\section{Article history:}

- $\quad$ Received 25 March 2016

- $\quad$ Accepted 20 May 2016 